\title{
Governance of Sexual Functioning by General vs. Special Psychological Mechanisms Remains an Empirical Issue
}

\author{
Jacques J. D. M. van Lankveld • Moniek ter Kuile
}

Published online: 9 July 2009

(C) The Author(s) 2009. This article is published with open access at Springerlink.com

The discussion started by Binik and Meana (2009) is, in our opinion, a very well-timed and welcome initiative. We agree with their argument that development in isolation might bring high costs and small benefits and that a critical evaluation of this position is very important at this moment in time to avoid the danger of losing connection with mainstream developments of psychological therapies.

A special position of sex therapy would indeed be warranted if we were strongly convinced that sex therapy does a good job and that other types of psychological therapy are unfit to treat sexual problems or that these are significantly less powerful in doing so than sex therapy. As Binik and Meana also mention, however, the outcome literature does not robustly demonstrate the superiority of sex therapy over "no treatment at all" or some form of placebo treatment (however difficult it may be to validly operationalize the latter in the field of psychology). Although Heiman and Meston (1997) identified "well-established" applications of sex therapy according to the American Psychological Association's Task Force criteria for male erectile disorder and female orgasmic disorder, the evidence to support this conclusion remains thin. To further illustrate this point, Cochrane Systematic Reviews on sex therapy are absent or conclude that good evidence is non-existent (e.g., for vaginismus: McGuire \& Hawton, 2001). In contrast, such reviews do show the efficacy of cognitive-behavioral therapy for a

J. J. D. M. van Lankveld ( $\square)$

Department of Clinical Psychological Science,

University of Maastricht, P.O. Box 616,

6202 MD Maastricht, The Netherlands

e-mail: J.vanLankveld@dep.unimaas.nl

M. ter Kuile

Department of Psychosomatic Gynecology and Sexology, Leiden

University Medical Centre, Leiden, The Netherlands large array of mental disorders (e.g., bulimia nervosa: Bacaltchuk, Hay, \& Trefiglio, 2001; chronic fatigue syndrome: Price, Mitchell, Tidy, \& Hunot, 2008, and generalized anxiety disorder: Hunot, Churchill, Teixeira, \& Silva de Lima, 2007). However, there is remarkable evidence on the other side of the balance, which supports the efficacy of bibliotherapy versions of sex therapy. In a meta-analysis of controlled outcome studies, van Lankveld (1998) found that this was the case for female orgasmic disorder and male premature ejaculation.

Thus, on the basis of such shallow empirical evidence, it appears unjustified to maintain that sex therapy, at least in a therapist-delivered format, should occupy a special position. Reconceptualizing sexual dysfunctions into theoretical frameworks that thrive in other areas of psychology has the advantage of bringing in a vast and new knowledge base. To give an example, our research of female lifelong vaginismus has profited from making such a conceptual shift. Whereas the standard treatment for this problem type as described in sex therapy handbooks has repeatedly been claimed to be very successful, with response percentages sometimes approaching 100\% (Masters \& Johnson, 1970), our results were quite disappointing when we subjected this treatment to a rigorous empirical test (van Lankveld et al., 2006). While we made, in our view, every effort to give women with this condition the maximum opportunity to profit from an intervention package including sexual psychoeducation, relaxation training, sensate focus exercises, gradual exposure, and progressive vaginal penetration, in the end only about $20 \%$ of the women were able to have sexual intercourse. Although significantly efficacious, compared with the nil results in the waiting-list control group, this outcome in no way even approached the previously claimed results. When analyzing treatment process data in this study, a strong resemblance of the pattern of results to the phenomenology of certain phobic disorders emerged (ter Kuile et al., 2007). An obvious next step was to reframe the 
treatment of lifelong vaginismus as a "vaginal penetration phobia." This led us to suggest therapist-aided and prolonged exposure as a crucial treatment ingredient. The approach that was subsequently developed consisted of a maximum of three, $2 \mathrm{~h}$ exposure sessions during 1-week. The exposure was selfcontrolled, i.e., the participant performed the vaginal penetration exercises by herself, while an experienced female behavior therapist gave instructions how to do the exercises and motivated her to expose herself to the anxiety-provoking penetration stimuli. Exposure homework with the partner between sessions was also involved. Two follow-up sessions were scheduled over a 5 week period to discuss homework. Pilot testing in a replicated single-case design, in which the data of 10 participants were analyzed using randomization tests (Edgington \& Onghena, 2007), showed a large treatment effect. Nine out of ten participants reported having had penilevaginal intercourse after treatment and in five out of nine responders, intercourse was accomplished within the first week of treatment. These results remained at a 1 year follow-up (ter Kuile et al., 2009). A subsequent randomized, waiting-list controlled study $(N=50)$ of women with lifelong vaginismus demonstrated that, after the exposure week, $80 \%$ of the treated women were able to have intercourse, again compared with none in the waiting-list condition. The percentage of responders further increased to $96 \%(n=24)$ after 4 weeks of treatment (ter Kuile, 2008). Reconceptualizing vaginismus as a phobic disorder thus helped us in developing a new perspective on its treatment that appears more promising than what was repeatedly advocated as the treatment of choice for decennia in a row. Of course, replication of our results is needed.

As stated by Binik and Meana, psychological research into sexuality has, to a large extent, developed in splendid isolation, dissociated from the remainder of the field of psychology. Due to this position, potentially productive crossfertilization may not have taken place. As we demonstrated for the case of lifelong vaginismus, there are indications that phenomena, previously considered as exclusively belonging to the special field of sexology, might have been elucidated at an earlier point in time if insights from other domains would have been applied. Without solid evidence of the opposite, the rule of parsimony would discourage us to presume that human sexual functioning is governed by a different set of rules and mechanisms from those in other domains.

Of course, this does not preclude that some aspects of sexuality might be special and different from other fields. Such differences might be associated with the special place that sexuality occupies in human functioning, in peer and partner interaction, and in the process of mate finding and bonding. This might give rise to reluctance to disclose intimate details of sexuality or difficulties in this domain, to selection bias in sex research, and to specific cognitive phenomena such as the "sexual content induced delay" in reaction time studies using sexual stimuli (Geer \& Bellard, 1996). Ultimately, the governance of sexual functioning by general versus special psychological mechanisms remains an empirical issue, to be addressed in sound scientific study.

Open Access This article is distributed under the terms of the Creative Commons Attribution Noncommercial License which permits any noncommercial use, distribution, and reproduction in any medium, provided the original author(s) and source are credited.

\section{References}

Bacaltchuk, J., Hay, P., \& Trefiglio, R. (2001). Antidepressants versus psychological treatments and their combination for bulimia nervosa. Cochrane Database of Systematic Reviews, Issue 4. Art. No.: CD003385. doi:10.1002/14651858.CD003385.

Binik, Y.M., \& Meana, M. (2009). The future of sex therapy: Specialization or marginalization? Archives of Sexual Behavior, 38, doi:10.1007/ s10508-009-9475-9.

Edgington, E. S., \& Onghena, P. (2007). Randomization tests (4th ed.). Boca Raton, FL: Chapman \& Hall/CRC.

Geer, J. H., \& Bellard, H. S. (1996). Sexual content induced delays in unprimed lexical decisions: Gender and context effects. Archives of Sexual Behavior, 25, 379-395.

Heiman, J. R., \& Meston, C. M. (1997). Empirically validated treatment for sexual dysfunction. Annual Review of Sex Research, 8, 148-194.

Hunot, V., Churchill, R., Teixeira, V., \& Silva de Lima, M. (2007). Psychological therapies for generalised anxiety disorder. Cochrane Database of Systematic Reviews, Issue 1. Art. No.: CD001848. doi:10.1002/14651858.CD001848.pub4.

Masters, W., \& Johnson, V. (1970). Human sexual inadequacy. Boston: Little, Brown.

McGuire, H., \& Hawton, K. (2001). Interventions for vaginismus. Cochrane Database of Systematic Reviews, Issue 2. Art. No.: CD001 760. doi:10.1002/14651858.CD001760.

Price, J. R., Mitchell, E., Tidy, E., \& Hunot, V. (2008). Cognitive behaviour therapy for chronic fatigue syndrome in adults. Cochrane Database of Systematic Reviews, Issue 3. Art. No.: CD001027. doi: 10.1002/14651858.CD001027.pub2.

ter Kuile, M. M. (2008). Is therapist-aided exposure in vivo more effective in the treatment of lifelong vaginismus than cognitive behavior therapy? Paper presented at the International Society for the Study of Women's Sexual Health (ISSWSH) Annual Meeting, San Diego.

ter Kuile, M. M., Bulté, I., Weijenborg, P. T. M., Beekman, A., Melles, R., \& Onghena, P. (2009). Therapist-aided exposure for women with lifelong vaginismus: A replicated single-case design. Journal of Consulting and Clinical Psychology, 77, 149-159.

ter Kuile, M., van Lankveld, J. J., de Groot, E., Melles, R., Nefs, J., \& Zandbergen, M. (2007). Cognitive-behavioral therapy for women with lifelong vaginismus: Process and prognostic factors. Behaviour Research and Therapy, 45, 359-373.

van Lankveld, J. J. (1998). Bibliotherapy in the treatment of sexual dysfunctions: A meta-analysis. Journal of Consulting and Clinical Psychology, 66, 702-708.

van Lankveld, J. J., ter Kuile, M., de Groot, E., Melles, R., Nefs, J., \& Zandbergen, M. (2006). Cognitive-behavioral therapy for women with lifelong vaginismus: a randomized waiting-list controlled trial of efficacy. Journal of Consulting and Clinical Psychology, $74,168-178$. 